Junko Muroi • Ayumi Uematsu • Tohru Yorifuji

\title{
Identification of a novel single base-pair polymorphism in the glutamate dehydrogenase (GLUD1) gene
}

Received: February 15, 1999 / Accepted: February 18, 1999

\begin{abstract}
A novel single base-pair polymorphism, G/A at ntd 955, was identified within the coding region of the glutamate dehydrogenase gene (GLUD1). This polymorphism should prove useful for the study of human disorders with altered ammonia and/or blood glucose levels.
\end{abstract}

Key words Glutamate dehydrogenase (GLUD1) gene · Single base-pair polymorphism $\cdot$ Chromosome 10q

\section{Introduction}

Glutamate dehydrogenase (EC1.4.1.3) is a ubiquitously distributed mitochondrial matrix enzyme which catalyzes the reversible conversion of glutamate to $\alpha$-ketoglutarate. The gene (GLUD1) spans about $45 \mathrm{~kb}$ on chromosome 10q21.1q24.3 and is split into 13 exons (Michaelidis et al. 1993).

Unlike brain-specific glutamate dehydrogenase, deficiency of which leads to a form of neurodegenerative disease (Plaitakis et al. 1988), the role of GLUD1 in human disease remained unknown until recently, when Stanley et al. (1998) identified activating mutations of GLUD1 in patients with hyperinsulinism-hyperammonemia syndrome. Most of the mutations lie in the guanosine triphosphate (GTP) binding site of the gene, which is essential for the GTP-mediated allosteric inhibition of the enzyme. However, there are other mutations outside the GTP binding site, suggesting that different mutations affect the enzyme activity differently.

In a previous attempt to determine mutations in patients with hyperinsulinism-hyperammonemia syndrome, we identified a novel single base-pair polymorphism, G/A at ntd 955, within the coding region of GLUD1 (Nakatani et al. 1988). Among the Japanese subjects studied, these two

J. Muroi $(\bowtie) \cdot$ A. Uematsu $\cdot$ T. Yorifuji

Department of Pediatrics, Kyoto University Hospital, 54 Shogoin,

Sakyo-ku, Kyoto 606-8507, Japan

Tel. +81-75-751-3293; Fax +81-75-752-2361

e-mail: muroi@kuhp.kyoto-u.ac.jp alleles showed similar gene frequency. Since this enzyme is a key enzyme connecting glutamate and energy metabolism, we believe this polymorphism should prove useful not only for the study of hyperinsulinism-hyperammonemia syndrome but also for the study of other disorders with altered ammonia and/or blood glucose levels.

Polymerase chain reaction (PCR) conditions

Since the mutation does not alter pre-existing restriction sites of the gene, we designed a mismatched primer pair so that in the presence of the G allele the PCR products would contain an $R s a$ I restriction site.

Forward primer:

5'-CAGGGATTTGGTAATGTGGGCGT-3'

Reverse primer:

5'-CCATCAGACTCACCAACAGC-3'

PCR was performed in 5- $\mu \mathrm{l}$ reaction mixtures containing $10 \mathrm{mM}$ Tris- $\mathrm{HCl}(\mathrm{pH} 8.3), 50 \mathrm{mM} \mathrm{KCl}, 1.5 \mathrm{mM} \mathrm{MgCl}_{2}$, $0.01 \%(\mathrm{w} / \mathrm{v})$ gelatin, $200 \mathrm{mM}$ of each dNTP, $5 \mathrm{pmol}$ of each mismatch primer, and 0.125 units of AmpliTaq Gold DNA polymerase (Perkin-Elmer, NJ, USA). The cycling parameters consisted of initial activation at $94^{\circ} \mathrm{C}$ for $10 \mathrm{~min}$ followed by 30 cycles of denaturation at $94^{\circ} \mathrm{C}$ for $1 \mathrm{~min}$, and annealing and extension at $53^{\circ} \mathrm{C}$ for $20 \mathrm{~s}$. The PCR products were digested with $R s a \mathrm{I}$ and electrophoresed on a $10 \%$ denaturing polyacrylamide gel.

Polymorphism and allele frequency

Figure 1 shows a representative result of the analysis. The allele frequencies of the polymorphisms among 33 Japanese individuals are shown in Table 1.

Table 1. Allele frequencies of the polymorphisms in 33 Japanese individuals

\begin{tabular}{ll}
\hline Allele & Frequency \\
\hline $\mathrm{G}$ & 0.59 \\
$\mathrm{~A}$ & 0.41 \\
\hline
\end{tabular}




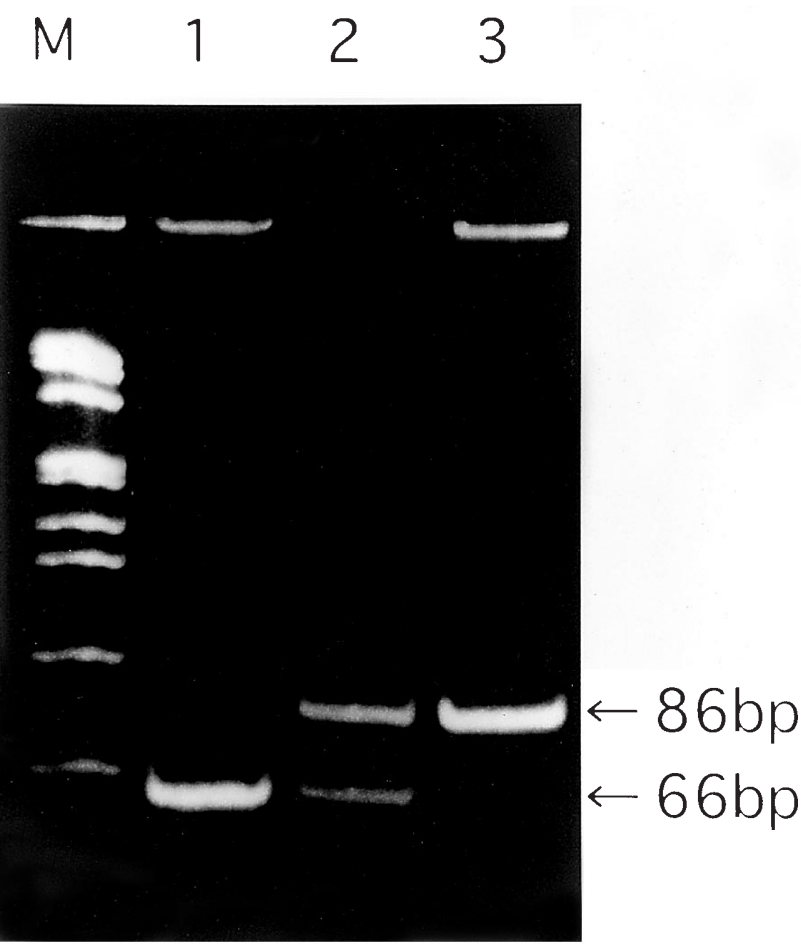

\section{References}

Michaelidis TM, Tzimagiorgis G, Moschonas NK, Papamatheakis J (1993) The human glutamate dehydrogenase gene family: gene organization and structural characterization. Genomics 16:161-168

Nakatani Y, Schneider M, Banner C, Freese E (1988) Complete nucleotide sequence of human glutamate dehydrogenase cDNA. Nucleic Acids Res 13:6237

Plaitakis A, Moschonas N, Papamatheakis J, Zannis B (1998) Glutamate dehydrogenase isoforms in the cerebellum of control subjects and patients with neurodegenerative disorders. DNA evidence for multiple genes encoding for human glutamate dehydrogenase. Ann Neurol 24:147-148

Stanley CA, Lieu YK, Hsu BYL, Burlina AB, Greeenberg CR, Hopwood NJ, Perlman, Rich BH, Zammarchi E, Poncz M (1998) Hyperinsulinism and hyperammonemia in infants with regulatory mutations of the glutamate dehydrogenase gene. New Engl J Med 338:1352-1357

Fig. 1. Representative result of the polymerase chain reaction (PCR)restriction fragment length polymorphism (RFLP) analysis. In the presence of the $\mathrm{G}$ allele, RsaI digestion of the PCR products generated two fragments, 20- and 66-bp in size. With the A allele, RsaI did not cleave the PCR product ( $86 \mathrm{bp}$ ). Lane $M, \varnothing \times 174$ DNA digested with Hae III; lane 1, homozygote for the A allele; lane 2; lane 3, homozygote for the $\mathrm{G}$ allele 